\title{
UPAYA MENGOBATI NESTAPA MANUSIA DI ERA REVOLUSI INDUSTRI 4.0 MELALUI KAJIAN KONSEP MANUSIA DALAM AJARAN MISTIK JALAL AD-DIN RUMI
}

\author{
Mulyadi Erman'), Muhammad Taufiq ${ }^{2)}$ \\ ${ }^{1)}$ Universitas Amikom Yogyakarta, \\ 2) Universitas Muhammadiyah Tasikmalaya, \\ e-mail: mulyadi.e@amikom.ac.id ${ }^{1)}$, mtaufiq@umtas.ac.id ${ }^{2)}$
}

\begin{abstract}
Abstraksi
Tujuan untuk memahami dan mengkaji secara mendalam konsep manusia dalam ajaran mistik Jalal ad-Din Rumi, dimana ke khasan dan keunggulan dari konsep tersebut dibanding dengan pandangan lain tentang manusia. Dipilihnya pendekatan mistik Rumi dalam memahami konsep manusia dilatar belakangi oleh suatu kondisi dimana pemahaman dan pengkajian manusia yang terlepas dari apek spiritual telah menyebabkan manusia kehilangan makna dan tujuan hidup yang bersifat eskatologis. Harapannya, kajian ini dapat memberikan kontribusi dalam dunia keilmuan dan sebagai upaya untuk mencari solusi terhadap dahaga spiritual dan krisis kemanusian di era revolusi indstri 4.0. Kajian ini merupakan kajian kepustakaan dengan objek buku/teks, laporan hasil penelitian, jurnal, dan sumber lainnya. Analisis dilakukan dengan interpretasi, koherensi-holistik, deskripsi dan analisis sintesis. Hasil kajian menunjukan bahwa manusia dalam ajaran mistik Rumi merupakan titik sentral dari tujuan penciptaan alam semesta. Manusia adalah mikrokosmos dan juga makrokosmos. Sebagai makrokosmos manusia merupakan manifestasi atau cermin dari kesempunaan perbendarahaan nama-nama Allah Yang Maha Suci. Sebagai mikrokosmos ia merupakan bagian dari alam yang diciptakan Allah menjadi khalifah dipermukaan bumi dengan tujuan memakmurkan bumi dengan keadilan, cinta dan kasih sayang.
\end{abstract}

Kata Kunci: Manusia, Revolusi Industri 4.0, Mistik, Rumi

\begin{abstract}
This study aims to understand and examine in depth the human concept in the mystical teachings of Jalal ad-Din Rumi, how the uniqueness and superiority of the concept compared with other views about humans. The choice of Rumi's mystical approach in understanding human concepts is based on a condition in which human understanding and study that is detached from the spiritual apek have caused humans to lose their eschatological meaning and purpose in life. The hope, this study can contribute in the scientific world and as an effort to find solutions to spiritual thirst and humanitarian crisis in the era of the industrial revolution 4.0. This study is a literature review with book/text objects, research reports, journals, and other sources. The analyst is carried out with interpretation, coherence-holistic, description and analysis of synthesis. The results of the study show that humans in Rumi's mystical teachings are central to the purpose of creation in the universe. Humans are a microcosm and also a macrocosm. As a macrocosm, man is a manifestation of the perfection of the names of the Most Holy God. As a microcosm, it is a part of nature that Allah created as a caliph on the surface of the earth with the aim of prospering the earth with justice, love and compassion.
\end{abstract}

Keywords: Man, God, Mystic, Rumi

\section{Pendahuluan}

Manusia merupakan makhluk misterius paling unik dari sekian makhluk Tuhan, baik dikalangan makhluk langit maupun makhluk bumi. Keunikan tersebut telah menarik perhatian para ahli dari berbagai latar belakang disiplin ilmu pengetahuan untuk menguak misteri kedirian manusia. Upaya para ahli untuk membuka tabir dibalik wujud fisik manusia telah melahirkan pergulatan intelektual yang sangat tajam dan alot dikalangan filosof, mystic dan ilmuan lainnya, mulai semenjak zaman klasik sampai era modern.

Adapun ilmuan modern, dalam upaya mencari jawaban tentang apa dan siapa manusia, salah satu diantaranya adalah usaha yang dilakukan oleh Charles Darwin. Ia berkesimpulan bahwa manusia berasal dari spesies yang sama dengan makluk hidup dimasa lalu yang sudah mengalami kepunahan. Meskipun tidak secara langsung Darwin menyatakan bahwa manusia berasal dari kera. Akan tetapi kesimpulan dan penjelasan dalam bukunya The Descent of Man, terbit tahun 1871, bahwa manusia satu turunan dengan kera. Usaha Darwin untuk mencari jawaban tentang asal usul manusia tetap saja menyisakan satu ruang yang misteri bagi ilmu pengetahuan, terutama 
terkait dengan temuan antropologh dan biologh tentang fosil-fosil manusia purba. Apakah manusia purba tersebut memenuhi kriteri untuk didefenisikan sebagai manusia?, atau justru evolusi biologis sudah berakhir pada primata, sehingga Adam sebagai nenek moyang manusia modern bukan hasil evolusi, melainkan titik awal evolusi peradaban manusia.

Penjelasan materialistik tentang manusia yang lebih menekankan pada sosok makhluk jasmani semata sebagaimana dianut oleh sebahagian besar saintis Barat telah menjadi petaka bagi kemanusian itu sendiri. Manusia sering termanifestasi sebagai budak-budak produksi dan hewan-hewan ekonomi yang rakus, saling memangsa satu sama lain. Meminjam istilah Darwin natural selection berlaku nyata dalam kehidupan manusia sekarang, sehingga paradigma yang muncul dalam kehidupan bukan lagi pada pertanyaan, apa yang bisa dimakan, akan tetapi siapa yang bisa dimakan. Akhirnya yang kuat menindas yang lemah, negara-negara besar menindas negara kecil dan berlomba-lomba untuk menguasai sumber-sumber daya alamnya dengan berbagai dalih dan tipu muslihat. Kemiskinan, kebodohan, keterbelakangan dijadikan sebagai objek eksploitasi untuk memperoleh keuntungnan dalam bidang politik dan ekonomi para penguasa.

Sementara itu, kemajuan dalam bidang tekhnologi informasi, khusunya di era revolusi industri 4.0, telah mampu menghilangkan sekat-sekat fisik dunia dan pada akhirnya melahirkan satu tatanan dunia baru yang dinamakan dengan "dunia maya". Melalui sebuah benda canggih yang bernama smart phone atau gadget, dengan berbagai menu dan fasilatas media sosial yang tersedia, manusia mampu berselancar menelusuri setiap sudut dari belahan dunia dan juga melakukan transaksi secara digital melalui sistem e-commerce.. Kemajuan tersebut menyebabkan manusia kesulitan didalam membedakan antara dunia maya dengan dunia realitas, akibatnya manusia menjadi terasing dari dirinya dan kehidupannya. Bahkan tidak sedikit diantaranya yang kehilangan makna dan tujuan (meaning and pourpuse ) hidup. Sebagai mana yang dikatakan Yususf Qardhawi, bahwa manusia barat telah berhasil membuka selubung pengetahuan, akan tetapi mereka tidak mampu menguak misteri di balik wujudnya[9].

Persoalan di atas merupakan sebuah masalah besar yang sedang melanda umat manusia diberbagai belahan dunia termasuk Indonesia, dan tanpa disadari telah menyeret hidup mereka keluar dari pusat lingkaran eksistensinya. Meskipun berbagai cara telah dilakukan untuk menanggulangi persoalan ini, akan tetapi belum berhasil menyentuh persolan mendasar dari kemanusian itu sendiri, bahkan terkadang justru memunculkan persolan baru. Di sisi lain, dunia barat yang telah berhasil mengalami kemajuan luar biasa dari segi materi, ternyata gagal memahami manusia sebagai makhluk yang multi dimensi atau makhluk yang mono pluralis[8]. Manusia bukan hanya sebatas makhluk yang mengandalkan kemampuan indera dan akal, tetapi lebih dari itu ia adalah makhluk Tuhan yang mengemban amanat untuk menjadi khalifah di permukaan bumi, untuk kemudian dipertanggungjawabkan dihadapan-Nya. Untuk itu sebuah pengkajian terhadap manusia, dengan meminjam istilah Mulyadhi Kartanegara yang bernuansa "humanis-eksistensial"[6] sebagaimana yang digagas Jalal al-Din Rumi di dalam ajaran mistiknya sangatlah dibutuhkan, terutama dalam rangka menyelamatkan manusia dari kehancuran, yaitu dengan cara mengembalikan manusia pada hakikat penciptaan dan eksistensinya sebagai teofani Tuhan paling sempurna yang mampu memantulkan ke-Agungan dari nama-nama-Nya.

Jalal ad-din Rumi merupakan seorang mistikus Islam yang berpandangan bahwa manusia merupakan mikrokosmos dan makrokosmos. Sebagai mikrokosmos manusia merupakan bahagian daria alam, sedangkan sebagai makrokosmos, alam diciptakan justru karena Allah ingin menciptakan manusia. Meskipun manusia pendatang akhir di alam semesta akan tetapi ia merupakan tujuan dari penciptaan semesta. Manusia adalah makhluk yang paling sempurna yang mampu memantulkan kemahakuasaan Allah.

Adapun alasan kenapa Rumi yang dijadikan sebagai objek pengkajian dalam penelitian ini, karena pemahaman tentang konsep manusia melalui pendekatan ajaran mistik sebagaimana digagas oleh Jalal al-Din Rumi sangat relevan dalam rangka menemukan jati diri manusia dan solusi yang memungkinkan menyelesaikan persoalan kekeringan spritual dan krisis kemanusian di era revolusi industri 4.0. Menurut Rumi dengan potensi Ilahiah yang diberikan Allah kepada manusia memungkinkan manusia untuk menjadi manusia ideal (al-Insan alKamil) sebagai wakil Allah di muka bumi yang menebarkan cinta, kasih sayang dan kedamaian.

Bertitik tolak dari latar belakang masalah di atas, maka persoalan pokoknya yang akan dikaji dalam tulisan ini adalah: a) Bagaimanakah pandangan mistik Jalal ad-din Rumi tentang kedudukan manusia? b) Bagaimanakah relevansi dari gagasan kemanusian dalam ajaran mistik Rumi untuk menyelesaikan krisis kemanusian di era revolusi industri 4.0 ?

Tujuan penelitian ini untuk mengkaji dan memahami secara komprehensif kedudukan manusia dalam ajaran Rumi berdasarkan pendekatakan mistiko fenomenologis. Dan juga mengaji relevansinya dalam penyelesaian krisis kemanusian dewasa ini. Manfaat pengkajian kedudukan manusia dalam ajaran Mistik Rumi

1. Mengungkap secara komprehensip konsep manusia dalam adalam ajaran mistik Jalal ad-Din Rumi

2. Merubah paradigma yang keliru dalam memberikan penilaian terhadap ajaran mistik

3. Penelitian ini merupakan salah satau upaya keilmuan untuk melengkapi penelitian-penelitian sebelumnya.

Adapun penelitian dan tulisan terkait Jalal ad-Din rumi, pernah dilakukan diantanya, yaitu buku yang ditulis oleh Mulyadhi Kartanegara, dengan judul "Renungan Mistik Jalal ad-din Rumi”, buku ini hanya menguraikan 
tentang pokok ajaran mistik rumi secara umum. Meskipun ada beberapa buku dan penelitian tentang Rumi dalam bahasa Indonesia tetapi tidak satupun yang mengkhususkan tentang konsep manusia dalam ajaran mistiknya, seperti buku kedua di susun oleh Saiful Jazil dkk., dengan judul "Senandung Cinta Jalal ad-din Rumi" Buku ini berisikan tentang puisi-puisi Rumi dalam mengekspresikan rasa cinta dan kedekatannya dengan Allah. Sementara dalam literatur Inggris ditemukan penelitian yang dilakukan oleh Khalifa Abdul Hakim, dengan judul Rumi, Neitzsche dan Iqbal, dan yang kedua penelitian yang dilakukan oleh Nicolson dengan judul "Rumi Poet and Mystic".

Penulis juga telah melacak pada beberapa situs di internet seperti Google.com, Amazon.com., Questia.com., dan sebagainya. Penelitian yang mengkhususkan tentang konsep manusia dalam ajaran rumi, khususnya kaitannya dengan upaya mengobati nestapa di era revolusi industri 4.0 belum ditemukan. Meskipun demikian penilitian yang pernah ada, baik dalam bentuk buku maupun artikel dapat menjadi sumber rujukan dalam menyempurnakan tulisan ini.

\section{Landasan Teori}

Manusia merupakan makhluk yang unik sehingga tidak ada suatu teori standar yang mampu memahami hakekat dan kedudukan manusia secara utuh dan total, masing-masing teori dengan kekhasan masing-masing mempunyai kekurangan dan kelebihan sendiri-sendiri[4]. Teori realisme klasik menyatakan bahwa manusia mempunyai hakekat rangkap, yang terdiri dari kwalitas fisik dan kecerdasan pada karya John Wild tahun 1948.

Sementara teori Materialism Historis berpendirian bahwa yang dikatakan manusia ialah apa yang mereka kerjakan, sebab itu yang menentukan hakekat manusia ialah tingkah laku atau tindakan bukan esensi. Tingkah laku disini adalah suatu kemampun untuk berkompetisi dalam kelas-kelas yang saling bertentangan utuk memenuhi kebutuhan-kebuhan hidup yang berupa materi dalam sebuah perubahan[7].

Sastra Prateja (1982: ix - xiv)[13], sangat sulit untuk memperoleh gambaran paripurna tentang manusia. Oleh karena itu konsep totalitarian tentang manusia perlu dihindari, karena manusia merupakan makhluk historis, yaitu hakikat manusia sendiri adalah suatu sejarah, suatu peristiwa dan bukan semata-mata suatu datum, sehingga sesuatu tentang hakikat manusia dapat dipahami dalam perjalan sejarah manusia itu sendiri.

Teori koherensi berpendapat bahwa suatu pernyataan dianggap benar, bila pernyataan itu bersifat koheren atau konsisten dengan pernyataan sebelumnya yang dianggap benar[15]. Menurut teori kebenaran ini, koherensi dan konsistensi yang menjadi kriteria utama kebenarannya. Hal itu menunjukkan dengan jelas bahwa teori koherensi ini tidak hanya mensyaratkan koherensi dan konsistensi, tapi juga sesuai dengan hukum-hukum logika. Apabila suatu pernyataan tidak sesuai dengan dalil-dalil logika, maka pernyataan tidak bisa diakui kebenarannya.

Rumi dalam memahami hakekat dan kedudukan manusia melalui pendekatan mistiko fenomenologis mencoba untuk menghindar dari hukum-hukum logika yang hanya berdasarkan rasio, karena pemahaman mistik lebih mengarah ke dalam melalui zauq atau qalb, ia merupakan physichology aspect, logika yang dipakai adalah logika hati nurani sebagai cognitive faculty. Manusia tidak hanya dipahami seperti halnya benda mati atau mesin, akan tetapi ia selalu mendunia dan menjadi sentral dan relasional dengan alam sekitarnya.

\section{Metode Penelitian}

Penelitian ini merupakaan penelitian kepustakaan (library research) dengan menitik beratkan pada konsep manusia dalam ajaran mistik Jalal ad-din Rumi dengan melakukan langkah penelitian sebagai berikut: 1. Pengumpulan dan Klasifikasi Data

Bahan-bahan dikumpulkan bersumber dari data primer dan sekunder, sumber data primer dilacak melalui buku maupun jurnal yang ditulis langsung oleh Jalal ad-din Rumi. Buku-buku tersebut antara lain:

a. The Mathnawi of Jalalu'ddin Rumi. Vol. I - VI. Ter. Nicholson,

b. The Sufi Path of Love; The Spiritual Teaching of Rumi, Terj. William C. Chittick,

c. Divan-i Shams-i Tabriz, seleksi\&terj. Nichollson,

Selain data yang bersumber dari buku-buku di atas, juga mengunakan buku-buku dan artikel peneliti terdahulu tentang Rumi sebagai pelengkap dan mempertajam analisis, Tidak tertutup kemungkinan dari beberapa sumber skunder dapat diperoleh data primer. Adapun pengumpulan data primer dan sekunder dilacak dari bahanbahan yang ada di perpustakaan maupun secara online lewat internet

Data yang telah terkumpul selanjutnya diklasifikasikan dalam suatu tema sentral guna dijadikan objek kajian. 2. Analisis Data

Data yang telah diklasifikasikan kemudian diteliti dengan menggunakan metode hermeneutik filosofis yaitu mengkaji teks-teks yang ada pada sumber baik primer maupun sekunder secara filosofis menggunakan langkah-langkah, yaitu interpretasi, holistika dan heristika. Sehingga diperoleh pemahaman yang menyeluruh dari sumber-sumber yang ada untuk melihat ide-idenya secara utuh tentang hal-hal yang bersifat perenial filosofis secara akurat dan komprehensif tentang konsep manusia dalam ajaran mistik Rumi. Selanjutnya dilakukan analisa filosofis terhadap hasilnya sehingga diperoleh suatu kesimpulan yang bisa diuji kebenarannya. 


\section{Pembahasan}

Jalal ad-din Rumi, dilahirkan di Balkh (Afganistan sekarang) pada tahun 1207 M[2]. merupakan seorang mistikus Islam yang mempunyai pengaruh besar terutama melalui karya-karya mistiknya, tidak saja pada dunia Islam seperti Persia, Turki, Mesir, Indian serta negara Islam lainnya, tetapi juga di dunia Barat. Di dunia Barat ajaran mistik Rumi di kenal dengan "whirling dervishes" atau darwis yang berputar[1]. Bahkan Iqbal menyebut karya-karya Rumi dengan "buku tertutup yang penuh dengan hikmah dan rahasia”[5]. Tidak semua orang bisa memahami karya-karya tersebut, karena sarat dengan simbol-simbol dan makna metaforis yang sulit ditangkap maksudnya.

Seluruh karya-karyanya merupakan pokok-pokok ajaran spritual yang membimbing manusia untuk mencapai kesempurnaan dalam hidupnya. Adapun Masnawi adalah karya Rumi yang paling banyak membahas tentang hakikat dan kedudukan manusia dalam hubungannya dengan Allah dan alam semesta disamping karya-karyanya yang lain. Sehingga tidaklah berlebihan Jami (1414 - 1493) menyebut karya utama rumi al-Masnawi sebagai "Quran dalam bahasa persia". Sementara Rumi sendiri menyebutnya sebagai akar dari akarnya akar agama dalam hal menyingkap rahasia-rahasia pencapaian kebenaran dan kepastian[6].

Pandangan Rumi tentang manusia tidak dapat dilepaskan tentang pandangan ontologis dan juga kosmologisnya. Menurut Rumi alam adalah teofani dari sekian banyak nama Tuhan. Sebagian diantaranya memanifestasi dalam bentuk kemarahan Tuhan atau kekerasan Tuhan, sebagian yang lain memanifestasi dalam bentuk kasih sayang Tuhan yang melekat dalam setiap hakikat ilahi. Sifat kasih sayang, cinta dan keindahan Tuhan inilah yang selalu dirindukan oleh para mistikus untuk diungkapkan dalam segala hakikat sesuatu[1].

Pemikiran mistik Rumi di dasarkan pada pemahaman tentang adanya kesatuan wujud. Konsep ini menjadi landasan ontologis bagi pemahaman struktur wujud dalam ajaran mistiknya. Hal ini berbeda dengan pandangan filosof dan juga teologh, bagi Rumi dan juga para sufi lainnya wujud berati "realitas", dan tidak ada realitas kecuali satu-satunya Realitas Absolut, realitas ini yang disebut dengan al-Haqq atau Tuhan. Sedangkan bagi para filosof dan juga teologh, manusia dan juga alam meskipun dipandang relatif, akan tetapi diakui sebagai realitas wujudiah (eksistensial) yang eksis disamping eksistensi mutlak (Tuhan).

Pemahaman Rumi tentang kesatuan wujud ini didasarkan pada prinsip syahadat, atau pemberian kesaksian bahwa "tidak ada tuhan atau illah selain Tuhan (Allah)" sebuah ungkapan yang dikenal dengan kalimat tauhid, "Pernyataan yang menyatakan keesaan Tuhan. Sementara kata illah dalam kalimat tersebut dipahami sebagai Realitas dan menafikan semua realitas selain realitas-Nya. Adapun kata tauhid juga berasal dari akar kata yang sama sebagaimana wahdah, sebagaimana juga istilah-istilah yang lain seperti ahad dan wahid (satu) dan ahadiayyah atau wahdaniyyah yang berati keesaan atau kesatuan[14]. Dalam salah satu syairnya ia mengatakan: "Telah kusisihkan segala kegandaan: kulihat dua dunia satu adanya: Satu kucari, satu ku kenal, Satu kulihat, Satu kuseru. Dia yang awal Dia yang akhir, Dia yang lahir Dia yang Batin; Tiada kukenal yang lain, kecuali "Ya huw" dan Ya Man Huw". Aku Mabuk piala Cinta, dua dunia telah hilang dalam pandanganku [11].

Adapun ayat al-Quran yang dikutip oleh Rumi dalam syairnya adalah surat (al-Hadid/57:3), yang mengisyaratkan bahwa Dia yang awal Dia yang akhir mengacu kepada kenyataan bahwa "Realitas" itu adalah dasar dan asal yang memanifestasi (sani' atau pencipta) terhadap segala yang ada dan juga tujuan yang bersifat eskatologis yaitu sebagai tempat kembali mereka. Sementara Dia yang Lahir dan Dia yang batin mengacu kepada imanensi dan transendensi realitas tersebut.

Paham wihdah al-wujud ini juga mewarnai pandangan kosmologi Rumi, menurutnya sifat kasih sayang Tuhan nafs al-rahmani memanipestasi dalam kejamakan di alam semesta, akan tetapi manifestasi Tuhan pada alam yang plural tidak bisa dikatakan bahwa itu adalah wujud Tuhan atau Tuhan itu sendiri, ia hanya sekedar tajalli Tuhan, sebagaimana sekelompok orang yang sedang membawa air dalam bejana ketika mereka melihat kedalam bejana mereka akan melihat banyangan matahari dalam bejana mereka masing-masing, sepintas akan terkesan bahwa terdapat banyak matahari, akan tetapi itu bukanlah realitas matahari yang sebenarnya, karena hanya ada satu matahari yang eksis. Apa yang terlihat dalam bejana tersebut hanyalah sebagai manifestasi dari matahari yang satu. Dengan demikian sangat tidak tepat tuduhan yang menyamakan bahwa paham wihdah al-wujud sama dengan panteisme. Karena dalam paham panteisme kejamakan pada alam yang fenomenal juga diakui sebagai realitas Tuhan, sehingga terdapat banyak tuhan yang mewujudkan diri pada alam semesta.

Corak irfani yang sangat kental pada bangunan ontologis dan kosmologi Rumi juga mempengaruhi pemikiran rumi tentang hakikat kebenaran. Sebagaimana pandangan Rumi bahwa hanya ada satu realitas yaitu realitas Absolut. Dari sudut epistemologis ia juga berusaha untuk melenyapkan setiap unsur kemajemukan terhadap kebenaran. Sehingga yang ada hanyalah satu kebenaran yaitu kebenaran Absolut. Kebenaran yang didasarkan pada panca indra menurut Rumi adalah kebenaran yang rapuh. Orang harus mampu melampau pemahaman indrawi untuk sampai pada kebenaran Absolut yang tidak mampu melihat nomena di balik fenomena, bagaimana ia diharap bisa melihat "Realitas" di balik segala nomena. Seseorang yang tidak bisa melihat unta di atas menara, bagaimana mungkin mampu melihat jarum di mulut sang unta. Kau hanya melihat kendi, tapi akankah kendi dibuat kalau bukan karena air. Lampaui bentuk lahiriah kendi, carilah air yang tersembunyi. 


\section{Manusia sebagai Makrokosmos dan Mikrokosmos}

Rumi berpandangan bahwa manusia adalah tujuan akhir penciptaan alam semesta yang berada pada puncak evolusi biologis dan spiritual, dan merupakan akhir dari segala yang maujud. Rumi mengutip hadis Qudsi yang berbunyi, yaitu Kalau bukan karenamu tidak akan kuciptakan alam semesta ini". Meskipun yang menjadi lawan bicara di sini adalah Nabi Muhammad akan tetapi ini juga berlaku bagi seluruh manusia, karena Muhammad adalah simbol dari manusia yang sudah mencapai tingkkat kesempurnaaan (insan al-kamil).

Untuk menguatkan pendapatnya ini Rumi memakai perumpamaan buah. Bagaimana seorang tukang kebun mempersiapkan tahapan-tahapan mulai dari proses penyedian lahan sampai proses penanaman, pengairan dan pemeliharaan demi menghasilkan buah. Meskipun buah muncul paling akhir, ia merupakan tujuan utama dari tumbuhnya sebatang pohon, kalau bukan karena buah seorang petani tidak akan menanam dan memelihara sebatang pohon[2].

Rumi juga berpandangan bahwa sebagai tujuan akhir penciptaan maka manusia juga berfungsi sebagai makrokosmos dan mikrokosmos. Kedudukan manusia sebagai makrokosmos karena pada diri manusialah termanifestasi perbendaharaan Tuhan yang tersembunyi secara sempurna. Dengan demikian alam semesta merupakan pantulan dari hakikat rohaniah manusia, karena yang pertama diciptakan Allah adalah Nur muhammad[10]. Secara alegoris Rumi menggambarkan sebagai berikut:

So you are microcosm in form, the macrocosm in meaning.

The outward form of the branch is the origin of the fruit; but inwardly, the branch into existence for the fruit's sake.

If there had been no desire and hope for the fruit, why did the gardener plant the tree?

Therefore in meaning the fruit gave existence to the tree, even if in form the tree gave birth to the fruit [10].

Adapun sebagai mikrokosmos (dunia kecil), karena pada diri manusi terkandung segala unsur yang ada dalam kosmos, seperti mineral, tumbuh-tumbuhan, hewan, dan bahkan unsur malaikat dan juga unsur keilahian atau unsur yang bersifat spiritual. Ide manusia sebagai mikrokosmos bagi Rumi menurut Mulyadhi terkait dengan fakta bahwa manusia merupakan puncak evolusi alam semesta pada karya Mulyadhi tahun 2002: 46 [6]. Berkaitan dengan evolusi ini Rumi menjelaskan dalam Mathnawinya sebagai berikut:

Man came first to the realm of the minerals, and from them he fell in among the plants.

For years he lived among the plants and remembered nothing of mineral because of strife.

When he lift the plants and joined the animals, he remembered nothing of vegetative state.

Save only the inclination he feels towards it, especially at the time of spring and fragrant herbs ...

Then that Creator whom you know kept on pulling him from animality to humanity.

In the same way he passed from realm to realm, until now he is intelligent, knowledgeable, and strong.

He remembers not his first intellects, and he will leave this present intellect behind.

He will be delivered from this intellect full of avarice and cupidity and see hundreds of thousands of marvelous intellects [10].

Menurut Mulyadhi Kartanegara[6] konsep manusia dan teori evolusi alam yang ditawarkan Rumi mendahului beberapa tokoh pemikir evolusioner modern, seperti Lamarck, Darwin, Bergson, Teilhard de Chardin dll. Bahkan menurut Iqbal, Rumi mengungguli mereka, karena Rumi tidak saja menggagas teori evolusi, akan tetapi juga memberikan suatu antusiasme kehidupan masa depan biologis manusia yang luar biasa. Setelah mengadakan perbandingan kritis dan analitis terhadap teori evolusia modern, Iqbal berkesimpulan bahwa dunia hari ini membutuhkan seorang Rumi untuk menciptakan suatu sikap hidup yang penuh pengharapan dan untuk menyelamatkan nyala antusiasme kehidupan. 
Kedukan manusia sebagai mikrokosmos memberikan dua kesadaran yang sangat penting dalam kehidupan, pertama adalah kenyataan yang membuktikan bahawa manusia merupakan dunia kecil dimana pada diri manusia terkandung segala unsur yang ada pada alam. Ini memberikan satu kesadaran bahwa kehidupan manusia akan seimbang apabila adanya hubungan yang harmonis dengan alam, baik itu mineral, tumbuh-tumbuhan dan hewan. Hal ini juga terkait dengan tugas kekhalifahan yaitu untuk memakmurkan bumi. Kedua, menunjukkan bahwa kedudukan manusia sebagai mikrokosmos memberikan pemahaman bahwa manusia memiliki sebuaah evolusi kesadaran yang bertahap dimulai dari kesadaran yang rendah sampai kesadaran yang tinggi, tergantung dengan kualitas spritual yang dimilikinya, adapun tahap kesadaran tersebut, yaitu kesadaran mineral, kesadaran tumbuhtumbuhan, kesadaran hewan dan kesadaran insaniah atau sadar kosmis.

Kesadaran insanilah yang menekankan pada kwalitas spiritual terlihat menjadi titik tekan tentang konsep manusia dalam ajaran mistik Rumi. Dia berkeyakinan bahwa pemamahan materalistik telah menjadikan manusia kehilangan nilai-nilai kemanusian itu sendiri. Alasan ini dijadikan Rumi untuk mengkritik pandangan kelompok materialis dan filosof tentang manusia. Kaum materialis menurut Rumi telah kehilangan indera penglihatan batin sehingga tidak mampu memahami hakikat manusia yang terdalam dan juga gagal dalam memahami tujuan penciptaannya. Sementara filosof tidak sampai pada realitas sejati dari kemanusia itu sendiri, karena pembuktian mereka yang berdasarkan pada logic dan silogim hanyalah pantasi dan opini belaka. Filosof hanya memandang manusia sebagai mikrokosmos, karena melihat bentuk manusia yang fenomenal. Sementara sufi memandang manusia sebagai makrokosmos, karena melihat kebenaran sifatnya yang hakiki [10].

Pemahaman makrokosmos tentang manusia akan mengantarkan manusia pada puncak kesadaran dan sekaligus menjadi alasan kenapa Allah mengangkat manusia untuk menjadi khalifah atau wakil Tuhan di Bumi. Kesadaran ini akan mampu menyelamatkan manusia dari sebuah bencana global yaitu krisis moral dan krisis spiritual. Pemahaman ini juga akan menjadikan manusia menjadi arsitek yang bertanggung jawab terhadap dirinya, terhadap Tuhan dan terhadap laju evolusi peradaban manusia.

\section{Manusia sebagai Teofani Tuhan}

Rumi berkeyakinan bahwa alam merupakan manifestasi dari sifat-sifat Tuhan, karena itu tiap-tiap bagian di alam semesta mencerminkan sifat-sifat tertentu dari-Nya, sesuai dengan tingkatan eksisitensinya dari bagianbagian tersebut. Semakin tinggi tingkat wujud sesuatu semakin banyak sifat Tuhan yang termanifestasi padanya. Sebagai contoh benda-benda mineral, seperti bebatuan, logam dan yang lainnya juga memantulkan sifat-sifat Tuhan seperti kecantikan dan kekuasaan Tuhan, sebagai contoh sebutir debu yang mengandung juataan atom di dalamnya, dan dalam setiap atom terkandung kekuatan nuklir yang maha dahsyat. Hal ini secara tidak lansung menggambarkan kekuatan dan keperkasaan (jalal) Tuhan. Begitu juga dengan gempa, halilintar, badai, letusan gunung merapi semunya itu mencerminkan keperkasaan Allah.

Pada sisi lain keindahan Tuhan dapat ditangkap pada mineral, tumbuh-tumbuhan, hewan dan manusia, hal ini juga termasuk benda-benda angkasa. Keindahan Tuhan pada dunia mineral sebagai contoh dapat dilihat pada keindahan batu-batu mulia seperti zamrud, berlian, dan logam mulia lainnya. Demikian juga keindahan Ilalhi yang tercermin pada alam seperti hamparan bumi yang membentang dengan luas, dan gunung-gunung yang menjulang tinggi, bukit-bukit yang berbaris, hutan-hutan dengan keindahan flora dan faunanya, kebun anggur dan taman bunga, serta kicauan burung-burung yang begitu indah dan mempesona. Di samping itu keindahan laut, luas terhampar biru membentang dengan segala kekayaan dan keindahan yang ada didalamnya, kesemuanya itu mencerminkan keindahan Tuhan.

Selain itu, keindahan Tuhan juga tercermin pada angkasa raya, seperti awan yang berarak, pelangi, bintangbintang dan rembulan yang menghiasi angkasa di malam hari, semuanya mencerminkan keindahan Tuhan. Dengan demikian apabila kita kembali kepada pernyataan Rumi yang telah diuraikan sebelumnya bahwa manusia adalah mikrokosmos dan makrokosmos, dimana manusia mengandung segala unsur yang ada pada kosmis. Hal ini mengisyaratkan bahwa secara potensial manusia berkemampuan untuk menjadi cermin bagi seluruh sifat keilahian. Potensi yang dimiliki oleh manusia ini juga melebihi dari makhluk-makhluk Tuhan yang berakal lainnya seperti para malaikat Jin, sebagaimana yang dijelaskan dalam sebuah hadis Rasulullah SAW yang dikutip oleh Rumi[10]:

God the Most High created the angels and placed within them the intellect, He created the beasts and placed within them sensuality, and He created the children of Adam and placed within them sensuality and intellect. So he whose intellect dominates his sensuality is higher than the angels, and he whose sensuality dominates his intellect is lower than beasts (Matsnawia, Vol. IV: 1496-1497).

Sabda Nabi ini menggambarkan bahwa terdapat tiga corak makhluk, yaitu malaikat, manusia dan binatang. Disamping itu juga terdapat tiga corak manusia, yaitu manusia malaikat, manusia biasa dan manusia binatang. Malaikat adalah simbol pengetahuan dan binatang adalah simbol kebodohan[2].

Meskipun manusia memiliki potensi untuk menjadi cermin dari pengejawantahan perbendaharaan yang tersembunyi. Akan tetapi mengamati dari tingkatan manusia maka hanya para Nabi dan orang orang sucilah yang mampu menjadi cermin yang secara sempurna sebagai manifestasi dari sifat-sifat keilahian. Kebanyakan manusia 
baru mampu menjadi cermin kasar yang butuh pembersihan setiap saat hingga menjadi kaca yang bening. Hanya dengan kebeningan nurani dan pembersihan sifat ke akuan manusia akan mampu mencapai taraf insan kamil.

Dijadikannya manusia sebagai cermin pada dasarnya tidak terlepas dari tujuan penciptaan manusia dan tugas kekhalifahan, yaitu untuk mengejawantahkan perbendaharaan yang tersembunyi. Meskipun terdapat tingkatantingkatan pada manusia dalam memanifestasikan sifat-sifat keilahian. Semua itu merupakan batu ujian dalam proses evolusi kesadaran manusia menuju ketingkat insan kamil, sebagimana yang diisyaratkan dalam firman Allah: "Dia menguji kamu siapa yang lebih baik amalnya diantara kamu" (QS:67, 2). Kwalitas hasil dalam mengemban amanah, baik yang terkait dengan ibadah ritual maupun pengabdian kultural menjadi tolok ukur kesuksesan manusia di sisi Allah. Sebaik-baik manusia adalah manusia yang memberikan manfaat pada orang lain. Kebeningan hari, kearifan dan cinta merupakan manifestasi dari rahman dan rahim Allah yang dipantulkan oleh cermin hati yang telah tersucikan.

\section{Kesimpulan}

Berdasarkan uraian-uraian di atas dapat disimpulakan bahwa Jalal ad-Din Rumi dengan pendekatan ajaran mistiknya (tasawuf) menempatkan manusia sebagai manifestasi ciptaan Allah yang paling sempurna. Manusia adalah cermin yang sempurna yang menggambarkan ke maha Kuasaaan Allah. Inilah yang menjadikan manusia lebih mulia dari makhluk Allah lainnya, bahkan menurut Rumi, Allah tidak akan memerintahkan malaikat untuk sujud kepada Adam kalau tidak atas kemuliaan yang di berikan Tuhan kepada Adam. Pengejawantahan atau teofani Tuhan pada manusia inilah yang menjadikan manusia sebagai makhluk Allah paling sempurna atau insan kamil.

Ajaran Rumi memahami manusia sebagi insan kamil telah menempatkan manusia pada posisi sentral dalam kehidupan di dunia, yaitu sebagai puncak dari evolusi kosmos dan merupakan tujuan akhir penciptaan alam semesta. Adapun dalam hubungannya dengan alam manusia merupakan mikrokosmos dan juga makrokosmos, meskipun kelihatannya manusia muncul dari alam akan tetapi alam itu muncul justru demi manusia. Dengan demikian bagi Rumi, manusia hanya dapat dimengerti dengan baik bila dilihat sebagai hasil cinta kasih Allah sehingga kesuksesan manusia dalam hidupnya apabila ia mampu menjadi cerminan-Nya

Rumi tidak hanya melihat manusia dari sisi penamapakan lahiriah semata akan tetapi mampu melihat kepada esensi yang paling dalam dari kemanusian itu sendiri yaitu sebagai makhluk rohani. Penekanan pada aspek rohani memberikan peluang untuk mewujudkan manusia yang bertanggung jawab terhadap kemanusian dan keilahian. Penekanan pada aspek rohani ini juga memungkinkan manusia untuk kembali kepada titik atau lingkar eksistensinya, sehingga mampu menjadi arsitek bagi dirinya dan peradapannya dalam kerangka penghambaan kepada Tuhan. Pada era revolusi 4.0 ini yang kurang mendapat perhatian. selain menderita kekeringan spritual dan moral religius, mereka juga kehilangan tujuan hidup yang bersifat eskatologis. Manusia sebagi manifestasi dari yang ilahi harus mampu sebagai penebar kasih sayang dan cinta antara sesama makhluk Tuhan di bumi tanpa memandang perbedaan ras warna kulit dan keyakinan.

\section{Daftar Pustaka}

[1] Armstrong, Karen, 1993, A History of Gad, Ballantine Book, New York

[2] Chittick, William C., 1983, The Sufi Path of Love; The Spiritual Teaching of Rumi, State University of New York Press, Albani. New York.

[3] Cassirer, Erns, 1944, An Essay on Man, , Yale University Press. New Heaven.

[4] Erman, Mulyadi, 2005, The Human Position in The Universe (Comparative Mystical Studies Between Jalal ad-Din Rumi and Jhon of The Cross), [Tesis], Centere for Religion and Cross Cultural Studies UGM, Yogyakarata.

[5] Iqbal, Muhammad, 1976, Asrar-I Khudi, terj. Bahrum Rankuti, Bulan Bintang, Jakarta.

[6] Kartanegara, R. Mulyadhi, 1986. Renungan Mistik Jalal ad-din Rumi, Jakarta, PT. Duni Pustaka Jaya.

[7] Kattsof, Lois O., 1996, Pengantar Filsafat, terj. Soejono Soemargono, Yogyakarta, Tiara Wacana.

[8] Notonsgoro, 1974, Pancasila dasar falsafah Negara, Pantjutan Tujuh, Jakarta

[9] Qardawi, Yusuf, 1996, Epistemologi AL-Quran, Risalah Gusti, Surabaya.

[10] Rumi, Jalal ad-din, 1977, The Mathnawi of Jalalu, ddin Rumi, vol. I - IV. Ter. Nicholson, London, Luzac \& Co. Ltd.

[11] -------, 1898, Divan-I Shams-i Tabriz, seleksi \& terj. Nicholson, London, Cambridge University.

[12] -----------, Fihi ma Fihi, terj. Ing. Sing of the Unseen: The Discourse of jalal ad-Din Rumi. Abdullah Madjed \& CO. Kualalumpur, Malasia.

[13] Sastraprateja, (Ed), 1982, Manusia Multi Dimensional; Sebuah Renungan Filsafat, Jakarta, PT Gramedia.

[14] Scimel, Anemarie. 1996. Poetry and Mysticism in Islam, the Heritage of Rumi. The University of Cambridge, the Pitt Building, Trumpington Street, Cambridge, New York.

[15] Sumantri S., Jujun, 1987, Filsafat Ilmu Sebuah Pengantar Populer, Sinar harapan, Jakarta.

\section{Biodata Penulis}


Mulyadi Erman adalah salah satu dosen pengajar di Universitas Amikom Yogyakarta. Pada jurusan D3 Manajemen Informatika. Lulusan Fak Ushuluddin IAIN Imam Bonjol Padang pada tahun 1996. Lulus S2 Program Studi Ilmu Filsafat Universitas Gadjah Mada Yogyakarta pada tahun 1998 dan menyelesaikan studi S2 International Program Religion and Cross Cultural Studies UGM pada tahun 2005.

Muhammad Taufiq memperoleh gelar Insinyur, dari Jurusan Teknik Perminyakan UPN "Veteran” Yogyakarta, lulus tahun 1990. Tahun 2013 memperoleh gelar Magister Komputer (MKom) dari Program Magister Teknik Informatika STMIK AMIKOM Yogyakarta. Saat ini sebagai Dosen tetap di Universitas Muhammadiyah Tasikmalaya. 